Chronic Obstructive Pulmonary Diseases:

Journal of the COPD Foundation

Original Research

\title{
Marijuana Use Associations with Pulmonary Symptoms and Function in Tobacco Smokers Enrolled in the Subpopulations and Intermediate Outcome Measures in COPD Study (SPIROMICS)
}

Madeline A. Morris, MPH ${ }^{1}$ Sean R. Jacobson, MS ${ }^{1}$ Gregory L. Kinney, PhD, MPH $^{2}$ Donald P. Tashkin, MD $^{3}$

Prescott G. Woodruff, MD, $\mathrm{MPH}^{4}$ Eric A. Hoffman, $\mathrm{PhD}^{5}$ Richard E. Kanner, MD, MPH ${ }^{6,7}$

Christopher B. Cooper, $\mathrm{MD}^{3}$ M. Brad Drummond, MD, MHS ${ }^{8}$ R. Graham Barr, MD, DrPH, MPH ${ }^{9}$

Elizabeth C. Oelsner, $\mathrm{MD}^{9}$ Barry J. Make, MD ${ }^{1}$ MeiLan K. Han, MD, MS ${ }^{10}$ Nadia N. Hansel, MD, MPH ${ }^{11}$

Wanda K. O’Neal, $\mathrm{PhD}^{8}$ Russell P. Bowler, $\mathrm{MD}, \mathrm{PhD}^{1}$

\section{Abstract}

Background: Marijuana is often smoked via a filterless cigarette and contains similar chemical makeup as smoked tobacco. There are few publications describing usage patterns and respiratory risks in older adults or in those with chronic obstructive pulmonary disease (COPD).

Methods: A cross-sectional analysis of current and former tobacco smokers from the Subpopulations and Intermediate Outcome Measures in COPD Study (SPIROMICS) study assessed associations between marijuana use and pulmonary outcomes. Marijuana use was defined as never, former (use over 30 days ago), or current (use within 30 days). Respiratory health was assessed using quantitative high-resolution computed tomography (HRCT) scans, pulmonary function tests and questionnaire responses about respiratory symptoms.

Results: Of the total 2304 participants, 1130 (49\%) never, 982 (43\%) former, and 192 (8\%) current marijuana users were included. Neither current nor former marijuana use was associated with increased odds of wheeze (odds ratio [OR] 0.87, OR 0.97), cough (OR 1.22; OR 0.93) or chronic bronchitis (OR 0.87; OR 1.00) when compared to never users. Current and former marijuana users had lower quantitative emphysema $(P=0.004, P=0.03)$, higher percent predicted forced expiratory volume in 1 second (FEV $1 \%)(P<0.001, P<0.001)$, and percent predicted forced vital capacity (FVC\%) $(p<0.001, P<0.001)$. Current marijuana users exhibited higher total tissue volume $(P=0.003)$ while former users had higher air trapping $(P<0.001)$ when compared to never marijuana users.

Conclusions: Marijuana use was found to have little to no association with poor pulmonary health in older current and former tobacco smokers after adjusting for covariates. Higher forced expiratory volume in 1 second $\left(F E V_{1}\right)$ and forced vital capacity (FVC) was observed among current marijuana users. However, higher joint years was associated with more chronic bronchitis symptoms (e.g., wheeze), and this study cannot determine if long-term heavy marijuana smoking in the absence of tobacco smoking is associated with lung symptoms, airflow obstruction, or emphysema, particularly in those who have never smoked tobacco cigarettes.

\footnotetext{
Abbreviations: chronic obstructive pulmonary disease, COPD; Subpopulations and Intermediate Outcomes in COPD Study, SPIROMICS; high resolution computerized tomography, HRCT; odds ratio, OR; percent-predicted forced expiratory volume at 1 second, FEV $\mathbf{1} \%$; percentpredicted forced vital capacity, FVC\%; forced expiratory volume at 1 second, FEV1; forced vital capacity, FVC; confidence interval, CI; maximum mid expiratory flow, MMEF; Global initiative for chronic Obstructive Lung Disease, GOLD; preserved ratio impaired spirometry, PRIsm; modified Medical Research Council, mMRC; St George's Respiratory Questionnaire, SGRQ; longitudinal follow-up, LFU; total lung capacity, TLC; residual volume, RV; Hounsfield unit, HU; current smokers of both tobacco and marijuana, TM; current smokers of marijuana and former tobacco smokers, MS; current smokers of tobacco and never marijuana smokers, TS; never or former marijuana smokers and former tobacco smokers, NS; Akaike Information Criterion, AIC; body mass index, BMI; tetrahydrocannabinol, THC
} 
Funding Support: This study was supported by the National Heart, Lung, and Blood Institute (NHLBI R01HL 095432, R01 HL089856, R01 HL089897); and UL1 RR025680 from NCRR/HIH. The Subpopulations and Intermediate Outcome Measures in COPD Study (SPIROMICS) is funded by contract from the National Heart, Lung, and Blood Institute (HHSN268200900013C, HHSN268200900014C, HHSN268200900015C, HHSN268200900016C, HHSN268200900017C, HHSN268200900018C, HHSN2682009000019C, HHSN268200900020C)

Date of Acceptance: October 24, 2017

Citation: Morris MA, Jacobson SR, Kinney GL, et al. Marijuana use associations with pulmonary symptoms and function in tobacco smokers enrolled in the Subpopulations and Intermediate Outcome Measures in COPD Study (SPIROMICS). Chronic Obstr Pulm Dis. 2018;5(1):46-56. doi: https://doi.org/10.15326/jcopdf.5.1.2017.0141

\section{This article contains an online supplement.}

\begin{tabular}{l}
1 National Jewish Health, Denver, Colorado \\
\hline Department of Epidemiology, Colorado School of Public Health, \\
University of Colorado Anschutz Medical Campus, Aurora \\
\hline 3 Division of Pulmonary and Critical Care Medicine, David Geffen \\
School of Medicine, University of California at Los Angeles \\
4 Division of Pulmonary, Critical Care, Sleep and Allergy, \\
Department of Medicine and Cardiovascular Research Institute, \\
University of California San Francisco, School of Medicine, San \\
Francisco \\
5 Departments of Radiology, Medicine and Biomedical Engineering, \\
University of Iowa, Iowa City \\
6 University of Utah Health Sciences Center, Salt Lake City \\
7 Department of Biostatics and Informatics, Colorado School of \\
Public Health, University of Colorado Anschutz Medical Campus, \\
Aurora \\
8 Division of Pulmonary Diseases and Critical Care Medicine, \\
University of North Carolina at Chapel Hill \\
\hline 9 Columbia University, Division of General Medicine, New York, \\
New York
\end{tabular}

10 University Michigan Health System, Ann Arbor

11 Johns Hopkins University, Baltimore, Maryland

\section{Address correspondence to:}

Russell Bowler \& Madeline A. Morris

Department of Medicine, Division of Pulmonary Medicine National Jewish Health

Denver, Colorado

Telephone: (303)270-2014

Emails:bowler@njhealth.org

mamorris8@gmail.com

\section{Keywords:}

marijuana; tobacco; lung; pulmonary; cross-sectional; respiratory; smoking; forced expiratory volume; forced vital capacity; emphysema; chronic obstructive pulmonary disease; computed tomography scan; epidemiology

\section{Introduction}

Marijuana is typically consumed by burning ground flower, top leaves or bud (marijuana) in a filter-less cigarette or joint with or without tobacco and inhaling its smoke. ${ }^{1}$ Marijuana has a similar chemical makeup, including toxins, as smoked tobacco, aside from approximately 60 cannabinoids in marijuana and nicotine in tobacco. Marijuana is typically smoked with larger inhaled volumes and much longer breath holding times than tobacco ${ }^{2}$ however, marijuana users generally smoke far fewer joints than tobacco smokers smoke cigarettes. The effects of smoking marijuana on lung health are controversial. In healthy individuals or those with asthma, a single episode of smoking a joint may lead to an acute bronchodilator response. ${ }^{3-5}$ Contradicting these results, other studies have reported a higher prevalence of wheezing, cough and sputum (bronchitis) in marijuana users ${ }^{6,7}$; unlike the clear association between tobacco cigarette smoking and COPD, epidemiological data have reported conflicting associations between marijuana use and lung function. For example, some epidemiologic studies have found that marijuana use is associated with a reduction in the ratio of forced expiratory volume at 1 second $\left(F E V_{1}\right)$ to forced vital capacity (FVC) suggestive of obstructive lung disease. ${ }^{8,9}$ Other studies have reported mild increases in FVC, ${ }^{10-12}$ thought to be due to the deep breathing maneuvers of users, thus potentially accounting for a reduced $\mathrm{FEV}_{1} / \mathrm{FVC}$, independent of obstructive lung disease.

There are significant challenges to assessing the role of marijuana on lung function, including the impact of co-existent tobacco smoking on respiratory outcomes. One population study looked at the role of marijuana use alone, or in combination with tobacco use, on lung function tests. ${ }^{6}$ Both marijuana and tobacco use alone were associated with a significant reduction in $\mathrm{FEV}_{1} / \mathrm{FVC}$ but when assessed for interaction between marijuana and tobacco smoking status they found 
the effect of marijuana use in those who also smoked tobacco was to reduce this effect by $0.8 \%$ (95\% confidence interval [CI] $-1.8 \%$ to $3.4 \%) .{ }^{6}$ Similar results were found with FEV 1 and maximum midexpiratory flow (MMEF). Tan et al reported no association of marijuana alone with spirometricly-defined COPD in a random sample of Canadian adults >age 40, but they did observe a significant interaction between marijuana and tobacco. ${ }^{12}$ Other significant limitations to most previous research include bias on studying younger individuals ( $<50$ years of age) who are unlikely to show significant signs of lung disease even with significant tobacco exposure and few published studies have assessed emphysema by CT scan. ${ }^{6,13}$ To address some of these limitations we have investigated the relationship between self-reported marijuana use in the Subpopulations and Intermediate Outcomes in COPD Study (SPIROMICS) study.

\section{Methods}

\section{Population}

SPIROMICS (ClinicalTrials.gov Identifier: NCT01969 344 ) is an ongoing multicenter prospective observational study funded by the National Institutes of Health $(\mathrm{NIH})^{14}$ that enrolled 2982 individuals between November 2011 and January 2015. Individuals were recruited at university medical centers, and were 40-80 years old at the time of enrollment. The institutional review board at all sites approved the study protocol. Individuals ( $N=2982)$ were categorized as non-tobacco smokers ( $<1$ pack year; stratum 1) or smokers ( $>20$ pack years; stratum 2-4). Study participants provided written informed consent.

Participants were enrolled into 4 strata based on tobacco smoking history, post-bronchodilator FEV 1 / FVC ratio, and other lung function criteria. The analyses reported here include participants ( $N=2304)$ with >20 pack years who completed a short survey regarding marijuana use at the first visit. Never smoking controls ( $<1$ tobacco pack year history) were recruited and enrolled based on normal spirometric function and represent a non-random comparison group for marijuana exposure. Marijuana users in this group were known to have normal lung function at enrollment. Because of this recruitment bias, never tobacco-smoking controls ( $\mathrm{N}=157)$ were excluded from the analysis.

\section{Assessment of Marijuana Use}

Marijuana lifetime exposure and current use status were assessed at enrollment (online supplement Table 1). Marijuana use was categorized into current (use in the past 30 days), and former (use over 30 days ago) users and compared to never users. Those with a history of marijuana use estimated the number of bowls or joint equivalents smoked per week and how many years the participant had smoked marijuana (one bowl was equated to one joint in this analysis). This information was used to calculate the number of joint years which was kept as a continuous variable; 1 joint year is equivalent to smoking 1 joint or bowl per day for one year. A supplementary analysis was added to assess the impact of joint-year history with lung function and symptoms. Joint years were categorized into $<10,10-20$, and $>20$ joint-year history and compared to those who reported zero joint years.

\section{Clinical Data and Definitions}

Full details regarding the collection of clinical data have been described previously. ${ }^{14}$ COPD was defined as post-bronchodilator ratio of $\mathrm{FEV}_{1}$ to $\mathrm{FVC}<0.70$. We used Global initiative for chronic Obstructive Lung Disease (GOLD) guidelines ${ }^{15}$ to assess COPD severity as GOLD stages I-IV. Participants with FEV 1 / $F V C \geq 0.70$ and $F E V_{1}<80 \%$ were classified as preserved ratio impaired spirometry (PRISm). ${ }^{16}$

Respiratory health questionnaires included: the modified Medical Research Council (mMRC) dyspnea score, the Short Form Health Survey--SF-36, and the St George's Respiratory Questionnaire (SGRQ). Chronic bronchitis was defined as having 2 or more clinical criteria defined at their enrollment in the study. Acute exacerbations of respiratory disease were ascertained during the longitudinal follow-up (LFU) visit by asking "Since we last spoke, have you had an episode of increased cough and phlegm or shortness of breath, which lasted 48 hours or more?" If they answered yes, participants were further asked whether they received antibiotics or corticosteroids. Additional questions asked at each LFU contact included whether the participant urgently visited his/her doctor's office, went to an emergency department, or was hospitalized. Participants were considered to have experienced an exacerbation if they answered yes to receiving either antibiotic and/or systemic corticosteroids. A severe exacerbation was a report of visiting an emergency department and/or hospitalization for an acute 
episode of respiratory disease. The total number of exacerbations was the total number of events for which a participant received antibiotics and/or systemic steroids irrespective of treatment location. The interval time between assessments was 3 months. CT scans at total lung capacity (TLC) and residual volume (RV) were acquired at enrollment and at a 1-year return visit. ${ }^{17} \mathrm{CT}$ phenotyping was done using VIDA software on segmented lung images to measure lung volumes derived from imaging at TLC and RV. Metrics at TLC included mean lung attenuation, total lung tissue volume, and percent lung voxels falling below a threshold of -950 (emphysema). At RV, the percent voxels falling below 856 Hounsfield units (HU) (air trapping) were assessed.

\section{Data Analysis}

Cross-sectional analyses were conducted using $\mathrm{R}$ (version 3.3.1). Associations between respiratory symptoms and marijuana smoking status were examined using logistic regression adjusted for age, race, gender, $\mathrm{FEV}_{1} \%$, current tobacco smoking status, pack years, and joint years. Pulmonary function testing variables and total tissue volume were kept as continuous variables and assessed with simple linear regression. Percent-predicted $\mathrm{FEV}_{1}$ and FVC were adjusted for gender, race, height ${ }^{2}$, age ${ }^{2}$, current tobacco smoking status, joint and pack years. All other pulmonary function variables were adjusted for height and age in addition to the covariates listed above. Additional analyses of the combined effect of current tobacco and marijuana use status on lung function were assessed for potential interactions and adjusted for age ${ }^{2}$, height ${ }^{2}$, joint, and pack years. Participants were further categorized as: current smokers of both tobacco and marijuana (TM), current smokers of marijuana and former tobacco smokers (MS), current smokers of tobacco and never marijuana smokers (TS), and never or former marijuana smokers and former tobacco smokers (NS).

Emphysema severity was assessed with linear regression using stepwise selection; Akaike Information Criterion (AIC) is used to assign the most appropriate predictive covariates. Variables selected were age, gender, race, $\mathrm{FEV}_{1} \%$, tobacco smoking status, joint years, pack years, and body mass index (BMI).

\section{Data Analysis: Assessment of Joint-Year History}

Joint years were categorized into $<10,10-20$, and $>20$ joint years and compared to those with zero joint years. Cross-sectional associations between respiratory symptoms and joint-year history were examined using logistic regression adjusted for age, race, gender, $\mathrm{FEV}_{1} \%$, current tobacco smoking status, and pack years. Pulmonary function testing variables and total tissue volume were kept as continuous variables and assessed with simple linear regression. Percentpredicted $F E V_{1}$ and $F V C$ were adjusted for gender, race, height, height ${ }^{2}$, age, age ${ }^{2}$, current tobacco smoking status, and pack years. All other pulmonary function variables were adjusted for height and age in addition to the covariates listed above. Current marijuana use status was not adjusted for in these analyses to examine the effect of joint-year history as the primary explanatory variable.

For comparability, emphysema and percent air trapping were assessed using the same covariates selected for percent emphysema in the previous analysis of marijuana use status. Those covariates include age, gender, race, $\mathrm{FEV}_{1} \%$, tobacco smoking status, pack years, and BMI.

\section{Results}

\section{Participant Characteristics}

In a total of 2304 participants, 1130 (49\%) never, 982 (43\%) former, and 192 (8\%) current marijuana users are included. Participant characteristics are displayed in Table 1. Current marijuana users were more likely to be younger, white, and male than never users. They were also more likely to be current tobacco smokers and have less severe COPD. Joint years were significantly higher in current compared to former marijuana users, but there was a wide range in each group. BMI was significantly higher for former marijuana users when compared to never users.

Participant Characteristics: Assessment of Joint Years Further assessment of participant characteristics and joint years are included in the online supplement, Table 1b. Of the 2304 participants, 1610 (70\%) had zero joint years, 388 (17\%) had fewer than 10, 98 participants (4\%) had 10-20, and 208 (9\%) had greater than 20 joint years. Higher joint-year history was associated with younger age, being male, and white. Higher joint years was also associated with current tobacco smoking (as opposed to a former smoker), but lower tobacco pack years. 


\section{Table 1. Participant Characteristics}

\begin{tabular}{|c|c|c|c|}
\hline & \multicolumn{3}{|c|}{ Marijuana Use Status } \\
\hline & $\begin{array}{c}\text { Never } \\
(n=1130) \\
\%\end{array}$ & $\begin{array}{c}\text { Former } \\
(\mathrm{n}=982) \\
\%\end{array}$ & $\begin{array}{c}\text { Current } \\
(n=192) \\
\%\end{array}$ \\
\hline Age & $66.8 \pm 8.2$ & ${ }^{\mathrm{a}} 61.5 \pm 8.3$ & ${ }^{a} 58.6 \pm 8.6$ \\
\hline \multicolumn{4}{|l|}{ Gender } \\
\hline Male & 49.4 & ${ }^{\mathrm{a}} 55.9$ & ${ }^{\mathrm{a}} 60.9$ \\
\hline \multicolumn{4}{|l|}{ Race } \\
\hline White & 81.0 & ${ }^{\mathrm{a}} 74.7$ & ${ }^{\mathrm{a}} 70.3$ \\
\hline Height cm & $168.9 \pm 9.6$ & ${ }^{\mathrm{a}} 170.3 \pm 9.6$ & ${ }^{\mathrm{a}} 171.3 \pm 9.7$ \\
\hline Tobacco Use Status: & & a & a \\
\hline Former & 66.9 & 56.1 & 40.6 \\
\hline Current & 31.8 & 43.7 & 59.4 \\
\hline Tobacco Pack Years & $52.7 \pm 31.0$ & ${ }^{a} 46.7 \pm 22.5$ & ${ }^{\mathrm{a}} 46.0 \pm 27.5$ \\
\hline Joint Years & - & ${ }^{\mathrm{a}} 10.8 \pm 35.9$ & ${ }^{\mathrm{a}} 49.5 \pm 101.1$ \\
\hline $\mathrm{BMI} \mathbf{K} / \mathbf{m}^{2}$ & $27.8 \pm 5.1$ & $27.9 \pm 5.4$ & $\mathrm{~b}_{27.0 \pm 5.1}$ \\
\hline GOLD Stage: & & a & $\mathrm{a}$ \\
\hline control & 29.1 & 35.7 & 44.8 \\
\hline (1) & 13.7 & 14.9 & 18.8 \\
\hline (2) & 32.1 & 28.2 & 25.5 \\
\hline (3) & 18.3 & 13.7 & 8.3 \\
\hline (4) & 6.8 & 7.5 & 2.6 \\
\hline
\end{tabular}

Compared to never marijuana users, ${ }^{\mathrm{a}} p<0.01,{ }^{\mathrm{b}} p<0.05$; mean \pm

standard deviation are shown where indicated

BMI=body mass index; GOLD=Global initiative for chronic Obstructive Pulmonary Disease

\section{Respiratory Symptoms}

Neither current nor former marijuana use was associated with increased risk for cough, wheeze, or chronic bronchitis when compared to never marijuana users after adjusting for covariates (Figure 1).

Respiratory Symptoms: Analysis of Joint-Year History Cross-sectional analyses were performed to investigate associations of number of joint-year categories with respiratory symptoms (Online Supplement: Figure 1b). Those with either 10-20, or greater than 20 jointyear history were more likely to report wheeze (OR: 2.27, 1.09-5.39; RR: 1.66, 1.04-2.76) when compared to those with zero joint years. Chronic bronchitis was associated with those who had a greater than 20 jointyear history (OR:1.69, 1.19-2.39) when compared to those with zero joint years after adjustment for covariates.

\section{Airflow Obstruction and Emphysema}

Current and former marijuana smokers had significantly higher $\mathrm{FEV}_{1}(P<0.001, P<0.001), \mathrm{FEV}_{1} \%$
$(P<0.001, \quad P<0.001)$, FVC $(P<0.001, P<0.001)$, and FVC\% $(p<0.001, P<0.001)$ when compared to never users, even after adjustment for other predictive variables (Table 2). Current marijuana use was associated with a significantly higher $\mathrm{FEV}_{1} / \mathrm{FVC}$ ratio $(P<0.001)$ when compared to never userswhen adjusting for other predictive variables. Both current and former marijuana use was associated with significantly less quantitative emphysema ( $P=0.004$ and $P=0.03)$ and increased total tissue volume $(P=0.003)$ compared to never users, even after adjusting for age, race, gender, $\mathrm{FEV}_{1} \%$, current tobacco smoking status, pack years, and BMI (Figure 2). Former marijuana users showed higher percent air trapping $(P<0.001)$ while current use was not significantly different $(P=0.61)$ when compared to never marijuana users.

\section{Airflow Obstruction and Emphysema: Analysis of Joint Years}

Those with greater than 20 joint years had significantly higher FVC $(p<0.01), \mathrm{FEV}_{1}(P<0.05)$, and FVC\% $(p<0.01)$ when compared to those with zero joint years, even after adjustment for other predictive variables (online supplement: Table $2 \mathrm{~b}$ ). Those with 1020 joint years had significantly higher FVC $(P<0.01)$, and FVC\% $(P<0.05)$ when compared to those with zero joint years. A history of 0-10 joint years was associated with higher FVC $(P<0.05)$, and FVC\% $(P<0.05)$ when compared to those with zero joint years. Percent air trapping was significantly higher among those with 0-10 $(P<0.05)$ and $10-20(P<0.01)$ joint years when compared to those with zero joint years.

\section{Combined Use of Marijuana and Tobacco on Lung Health}

The effect of combined marijuana use with current tobacco smoking on lung function was further assessed by stratifying on current smoking status (Figure 3). After adjusting for covariates, both current tobacco alone and marijuana use alone resulted in a significant positive association with $\mathrm{FEV}_{1}(P<0.001, P<0.001)$, $\mathrm{FEV}_{1} \%(P<0.001, P<0.001), \mathrm{FVC}(P=0.07, P<0.001)$, FVC $\%(P<0.001, P<0.001)$ and $\mathrm{FEV}_{1} / \mathrm{FVC}(P<0.001$, $P<0.001)$, respectively, when compared to those smoking neither tobacco nor marijuana. Combined use of marijuana and tobacco showed a significant positive association with $\mathrm{FEV}_{1} \quad(P=0.02), \mathrm{FEV}_{1} \% \quad(P=0.02)$, FVC $(P=0.04)$, and FVC\% $(P=0.04)$ when compared to those who did not currently use tobacco or marijuana. 


\section{Figure 1. Respiratory Symptoms Among Current and Former Cannabis Users}

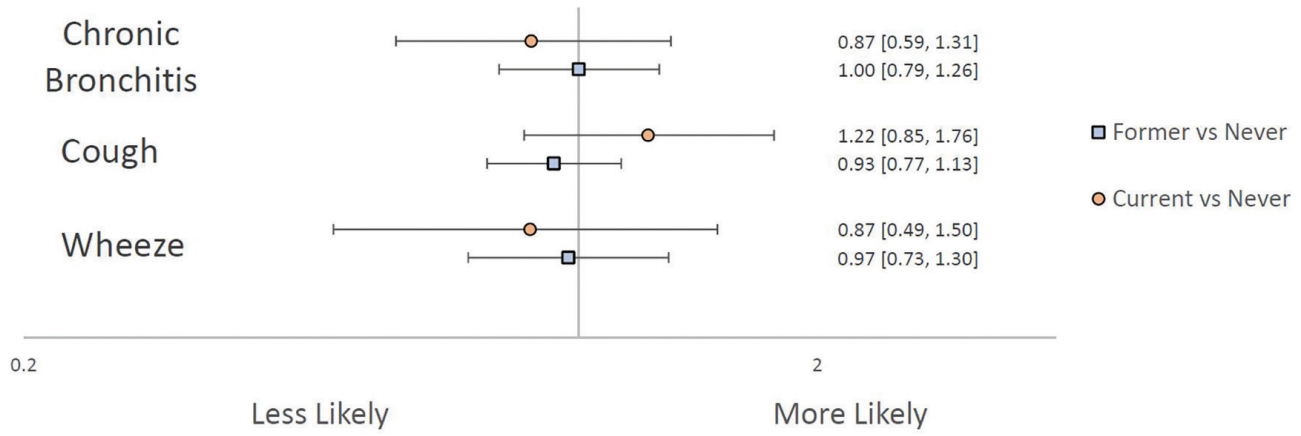

Multivariate analysis: odds ratios comparing former and current cannabis users to never cannabis users. Adjusted for age, race, gender, $\mathrm{FEV}_{1} \%$, current tobacco smoking status, pack years, and joint years.

\section{Table 2. Participant Radiographic Phenotype and Lung Function}

\begin{tabular}{|c|c|c|c|}
\hline & \multicolumn{3}{|c|}{ Marijuana Use Status } \\
\hline & $\begin{array}{c}\text { Never } \\
(n=1130) \\
(\mu \pm S D)\end{array}$ & $\begin{array}{c}\text { Former } \\
(n=982) \\
(\mu \pm S D)\end{array}$ & $\begin{array}{c}\text { Current } \\
(n=192) \\
(\mu \pm S D)\end{array}$ \\
\hline $\begin{array}{l}\text { Percent } \\
\text { Emphysema }\end{array}$ & $8.6 \pm 10.3$ & ${ }^{\mathrm{a}} 7.7 \pm 10.4$ & $\mathrm{~b}_{4.8} \pm 8.1$ \\
\hline $\begin{array}{l}\text { Percent Air } \\
\text { Trapping }\end{array}$ & $61.7 \pm 16.6$ & ${ }^{\mathrm{b}} 62 \pm 17.1$ & $58.6 \pm 19.1$ \\
\hline $\begin{array}{l}\text { Compared to ne } \\
\text { FEV }_{1} \% \text {, tobacco }\end{array}$ & $\begin{array}{l}\text { arijuana us } \\
\text { ting, pack } y\end{array}$ & $\begin{array}{l}\text { justed for a } \\
\text { nd BMI. }{ }^{a} p\end{array}$ & $\begin{array}{l}\text { nder, race, } \\
{ }_{p}{ }_{p<0.01}\end{array}$ \\
\hline $\mathrm{FEV}_{1} \%$ & $69.7 \pm 25.5$ & ${ }^{b} 75.0 \pm 27.3$ & ${ }^{b} 82.0 \pm 24.6$ \\
\hline FVC $\%$ & $89.2 \pm 18.1$ & ${ }^{\mathrm{b}} 92.9 \pm 18.6$ & ${ }^{\mathrm{b}} 95.4 \pm 17.4$ \\
\hline
\end{tabular}

Compared to never marijuana users; adjusted for age ${ }^{2}$, height ${ }^{2}$,

tobacco smoking status, pack years and joint years. ${ }^{\mathrm{a}} p<0.05,{ }_{p<0.01}$

\begin{tabular}{l|c|r|r}
\hline $\begin{array}{l}\text { Total Tissue } \\
\text { Volume (mL) }\end{array}$ & $858.5 \pm 176.6$ & $887.7 \pm 179.7$ & ${ }^{\mathrm{b}} 934.1 \pm 184.5$ \\
\hline FEV $_{\mathbf{1}}$ (L) & $1.9 \pm 0.9$ & ${ }^{\mathrm{b}} 2.2 \pm 0.9$ & ${ }^{\mathrm{b}} 2.5 \pm 0.9$ \\
\hline FVC (L) & $3.2 \pm 1.0$ & $\mathrm{~b}^{\mathrm{b}} 3.6 \pm 1.0$ & ${ }^{\mathrm{b}} 3.8 \pm 1.1$ \\
\hline FEV $_{\mathbf{1}} /$ FVC & $0.6 \pm 0.2$ & $0.6 \pm 0.2$ & ${ }^{\mathrm{b}} 0.7 \pm 0.1$ \\
\hline
\end{tabular}

Compared to never marijuana users; adjusted for age, age ${ }^{2}$, height, height ${ }^{2}$, gender, race, tobacco smoking, pack years and joint years.

${ }_{p<0.05,}{ }_{p<0.01}$ mean \pm standard deviation are shown where indicated

$\mathrm{FEV}_{1}=$ forced expiratory volume in 1 second; $\mathrm{FVC}=$ forced vital capacity

$\mathrm{FEV}_{1} / \mathrm{FVC}$ was not significantly different for combined current use of tobacco and marijuana $(P=0.09)$ compared to non-current smokers of either substance at enrollment after adjustment for covariates.

\section{Figure 2. Percentage of Emphysema Among Current, Former and Never Marijuana Smokers Stratified by Current Tobacco Smoking Status}

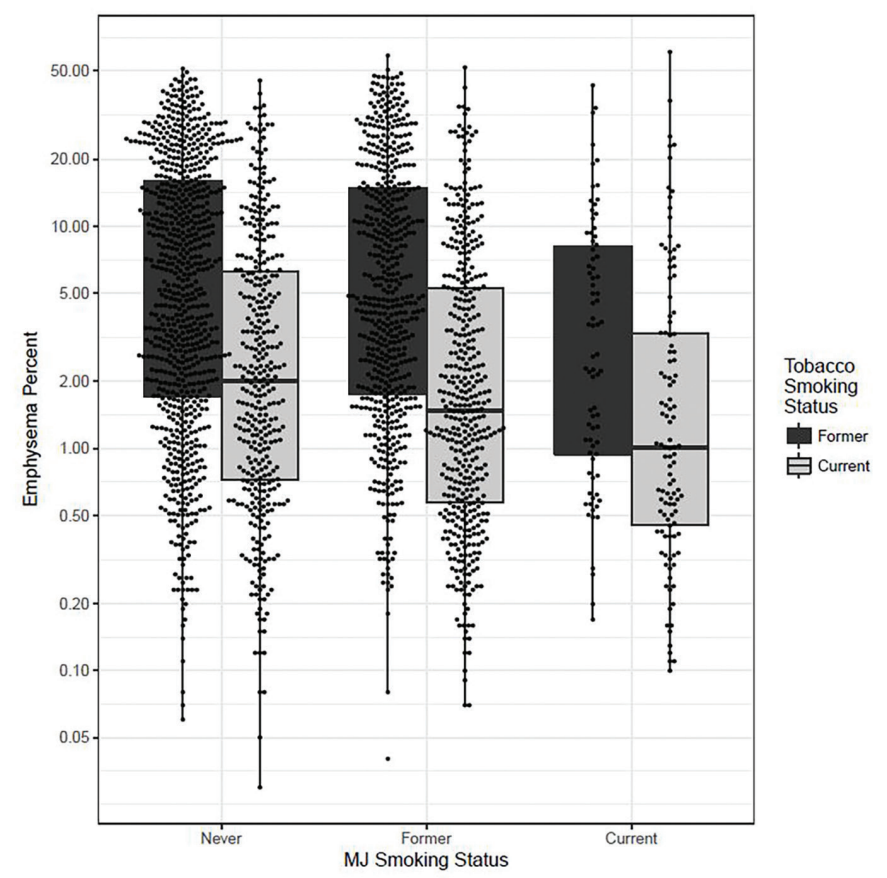

The box plots have been separated into panels. The lower horizontal line of each box represents the first quartile, the middle horizontal line within each box represents the median, and the box-segment above the median is the third quartile. The vertical line spans the lowest and highest datum still within 1.5 interquartile range of the lower and upper quartile, respectively. Data points outide the vertical line are outliers. 


\section{Figure 3. FEV $1 \%$ and $F V C \%$ Stratified by Current Smoking Status}

\section{Figure 3a.}

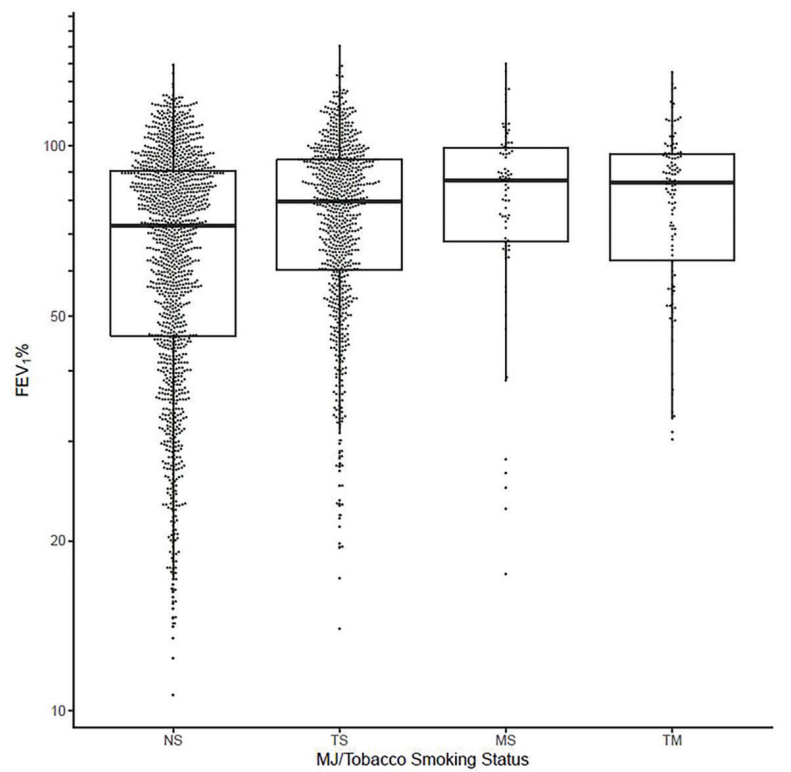

Figure 3b.

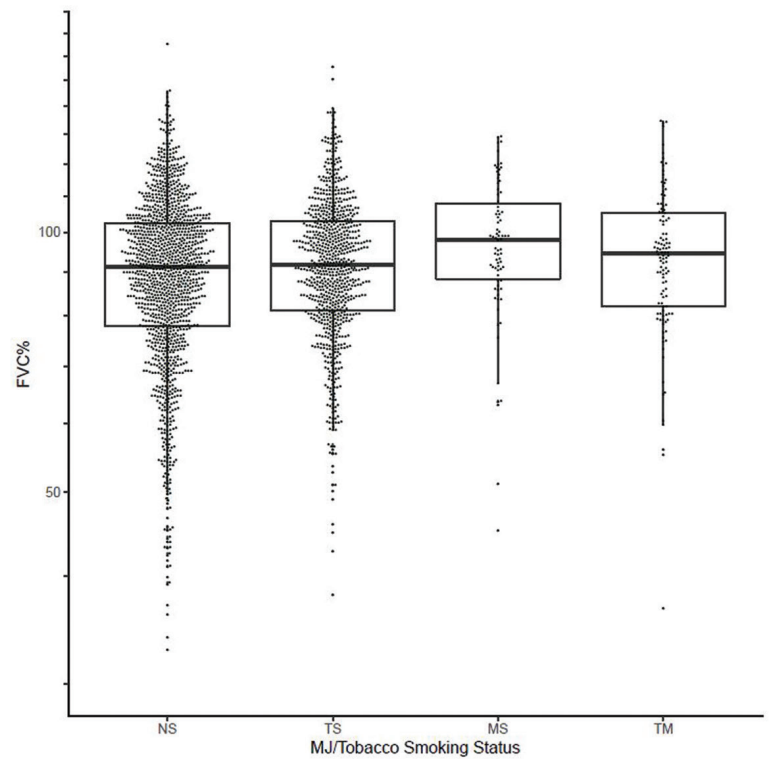

$\mathrm{FEV}_{1} \%$ (a) and $\mathrm{FVC} \%$ (b) stratified by current smoking status of tobacco alone, marjuana alone, and both tobacco and marijuana compared to non-use of either substance.The box plots have been separated into panels. The lower horizontal line of each box represents the first quartile, the middle horizontal line within each box represents the median, and the box-segment above the median is the third quartllie. The vertical line spans the lowest and highest datum still within 1.5 interquartile range (IQR) of the lower and upper quartile, respectively. Data points outide the vertical line are outliers.

$\mathrm{TS}=$ tobacco alone; $\mathrm{MS}=$ marijuana alone; $\mathrm{TM}=$ both tobacco and marijuana; $\mathrm{NS}=$ non-use of either substance

\section{Discussion}

This cross-sectional analysis of the association of marijuana history with measures of lung health is one of the first ${ }^{12}$ to include predominantly older adults and one of only a few studies that included a quantitative assessment of emphysema using CT scans. ${ }^{6,13}$ It is notable that nearly half (49\%) of the SPIROMICS cohort reported a history of marijuana smoking, although only $7 \%$ were considered active smokers. Similar to previously published studies, we find that marijuana smokers were more likely to be male and younger than non-users. ${ }^{18,19}$ Evidence for increase of cough, wheeze, and bronchitis among marijuana users varies in previously published studies ${ }^{6-8,12,20}$; however most show an increase in symptoms of chronic bronchitis in association with marijuana use. $^{5-9,20,21}$ We did not find that a history of marijuana use is associated with more wheezing, coughing, or bronchitis even after considering tobacco cigarette smoking. We did, however, find an increase in reported wheeze among those with a history of greater than 10 and 20 joint years. In agreement with other published studies, $6,7,12,21,22$ we also did not find that marijuana use was associated with more obstructive lung disease, but instead found an association between marijuana use and a higher FEV ${ }_{1}^{11}$ and FVC. ${ }^{10-12,23}$

Although not all published studies are in agreement, one of the more consistent lung function findings in marijuana literature is a higher FVC. ${ }^{10-12,22}$ While the mechanism for this is not clear, it could include deeper breathing of marijuana users. ${ }^{2,23}$ If $F E V_{1}$ is held constant, a higher FVC would be expected to be associated with a lower $F E V_{1} / F V C$, which could result in classification as mild obstruction. Interaction between marijuana and tobacco shows conflicting results; while one study found a synergistic effect of marijuana and tobacco such that marijuana when smoked along with tobacco augmented the impact of tobacco on the prevalence of COPD, ${ }^{12}$ there is opposing evidence to suggest that the effect of marijuana is to reduce the effect of tobacco on adverse pulmonary function. ${ }^{6}$ In SPIROMICS, lung function among combined tobacco and marijuana users was lower compared to non-smokers of either substance after adjusting for covariates. These results should be interpreted with caution since in this population, adults who have quit smoking tobacco or marijuana likely did so because of poorer health. 
There are also case series reporting lung bullae formation in marijuana smokers. ${ }^{23,24}$ While Aldington et al noted significantly greater lung attenuation in lung slices at the apices on CT scans in marijuana smokers derived from a random sample of residents of Wellington, New Zealand, they showed no significant increase of macroscopic emphysema on CT in their marijuana smokers. ${ }^{6}$ In agreement with these findings, our study found no evidence for increased extent of quantitatively scored emphysema in marijuana users nor any evidence of bullae. ${ }^{6,25}$

There are limitations to the interpretation of the results from this study. Mainly, this population is non-random and was recruited based on tobacco smoking history. Although we adjusted for tobacco use and excluded never tobacco smokers, it is still unclear if long-term heavy marijuana smoking results in significant risk of respiratory symptoms, lung obstruction, inflammation, or emphysema. The strong associations between tobacco smoking and adverse respiratory health may be masking effects of marijuana use. However, contemporaneous to the legalization of marijuana in many states, there has also been an exponential increase in the potency of tetrahydrocannabinol (THC) in marijuana from 3\% to now $30 \%$ or more. Thus, marijuana smoke exposure should be expected to decrease as potency increases since users would need to smoke less to achieve the desired level of intoxication. Moreover, there may be fewer individuals who have heavy marijuana smoking exposure, unlike many tobacco smokers for whom it is not uncommon to smoke 40-60 cigarettes per day. Another limitation is that marijuana was an illegal, schedule 1 substance in most of the United States at the time our participants were recruited. This may have biased against honest disclosure of marijuana use. Additionally, marijuana exposure can be more difficult to quantify because of sharing, differences in dosing and inhalation techniques, and methods to consume or use marijuana (e.g., vaping, dabbing, edibles). These newer methods of exposure may not have been fully quantified in the SPIROMICS cohort; however, the advanced age of the cohort suggests that smoking was the predominant marijuana delivery method. ${ }^{18,19}$ The analyses presented here adjust for joint years. It is difficult to quantify joint years since one joint or bowl is not universally comparable. This may explain why joint years was not shown to be a predictive covariate in any of our statistical models of current marijuana use status and pulmonary outcomes. Finally, marijuana and its effect on lung function was not the primary aim of the SPIROMICS study and there were only 192 active users. Although these results were able to detect differences in lung function and phenotypes among marijuana use groups, these results are not generalizable to a healthy adult population. There may be no to little increased risk of marijuana use for a further increase in respiratory symptoms or adverse effects on lung function among those with a history of concomitant tobacco use.

\section{Conclusion}

This cross-sectional analysis of participants enrolled into the SPIROMICs cohort was performed to investigate the relationships between marijuana use and pulmonary function and symptoms. Those enrolled were carefully screened and recruited based on tobacco use history and spirometric function and therefore, do not represent a random population of adults. Additionally, those included in this analysis reported $>20$ pack-year history of tobacco use. The relationships we found between tobacco use and pulmonary outcomes agree with a large body of research on the adverse pulmonary consequences of tobacco smoking (results not reported here). In contrast to tobacco smoking exposure, the illegality of marijuana use, up until recent years in select geographic areas, has made it a difficult target of epidemiologic observation. This study collected usage information on marijuana and reports on prevalence and associations of marijuana use among an older adult population with a history of heavy smoking, and lung health outcomes.

Previously reported findings of marijuana and pulmonary symptoms have led to conflicting conclusions. Our results indicate increased $\mathrm{FEV}_{1}$ and FVC among current and former users of marijuana even after controlling for other predictive variables. Evidence for a decreased ratio of $\mathrm{FEV}_{1} / \mathrm{FVC}$ with marijuana use has been supported $8,9,26,27$ but could be due to an increased FVC. ${ }^{9,26,27}$ This study also revealed a lower percentage of emphysema, yet a higher total tissue volume among current and former marijuana users and a higher percentage of air trapping among former users after adjustment for covariates. Percentage of emphysema and total tissue volume are inversely related; increased inflammation could explain these associations in our population. Analyses 
of an interaction between marijuana and tobacco smoking revealed increases in $\mathrm{FEV}_{1}$ and FVC among those who used marijuana only, tobacco only, and both marijuana and tobacco. These results are likely heavily biased and should be interpreted with caution. Those who quit smoking tobacco likely did so because of poorer health; contrary to those who continued to smoke tobacco. Among older adults with a history of tobacco use, marijuana use does not appear to increase risk for adverse lung function. It is necessary to collect more epidemiologic data on marijuana exposure in a broader population to better understand its health consequences.

\section{Acknowledgements:}

The authors thank the SPIROMICS participants and participating physicians, investigators and staffs for making this research possible. We would like to acknowledge the following current and former investigators of the SPIROMICS sites and reading centers: Neil Alexis, PhD; Wayne Anderson, PhD; R. Graham Barr, MD, DrPH; Eugene Bleecker, MD; Richard C. Boucher, MD; Russell Bowler, MD, PhD; Stephanie Christenson, MD; Alejandro P. Comellas, MD; Christopher B. Cooper, MD, PhD; David Couper, PhD; Gerard Criner, MD; Ronald G. Crystal, MD; Jeffrey L. Curtis, MD; Claire Doerschuk, MD; Mark Dransfield, MD; Christine M. Freeman, PhD; MeiLan K. Han, MD, MS; Nadia N. Hansel, MD, MPH; Eric A. Hoffman, PhD; Robert J. Kaner, MD; Richard Kanner, MD; Eric Kleerup, MD; Jerry Krishnan, MD, PhD;
Lisa LaVange, MA, PhD; Stephen C. Lazarus, MD; Fernando J. Martinez, MD, MS; Wanda O’Neal, PhD; Robert Paine, III, MD; Nirupama Putcha, MD, MHS; Steve Rennard, MD; Donald Tashkin, MD; Mary Beth Scholand, MD; Robert A. Wise, MD; and Prescott G. Woodruff, MD, MPH. The project officers from the Lung Division of the National Heart, Lung, and Blood Institute were Lisa Postow, $\mathrm{PhD}$, and Thomas Croxton, $\mathrm{PhD}, \mathrm{MD}$. SPIROMICS was supported by contracts from the National Institutes of Health/National Heart, Lung, and Blood Institute (HHSN268200900013C, HHSN268200900014C, HHSN268200900015C, HHSN268200900016C, HHSN268200900017C, HHSN268200900018C HHSN268200900019C, HHSN268200900020C), which were supplemented by contributions made through the Foundation for the National Institutes of Health from AstraZeneca; Bellerophon Therapeutics; Boehringer- Ingelheim Pharmaceuticals, Inc; Chiesi Farmaceutici SpA; Forest Research Institute, Inc; GlaxoSmithKline; Grifols Therapeutics, Inc; Ikaria, Inc; Nycomed GmbH; Takeda Pharmaceutical Company; Novartis Pharmaceuticals Corporation; Regeneron Pharmaceuticals, Inc; and Sanof.

\section{Declaration of Interest}

The authors report no conflicts of interest. The authors alone are responsible for the content and writing of the paper. 


\section{References}

1. Maertens RM, White PA, Williams A, Yauk CL. A global toxicogenomic analysis investigating the mechanistic differences between tobacco and marijuana smoke condensates in vitro. Toxicology. 2013;308:60-73.

doi: https://doi.org/10.1016/j.tox.2013.03.008

2. WU T-C, Tashkin DP, Djahed B, Rose JE. Pulmonary hazards of smoking marijuana as compared with tobacco. $N$ Engl J Med. 1988;318(6):347-351.

doi: https://doi.org/10.1056/NEJM198802113180603

3. Tashkin DP, Baldwin GC, Sarafian T, Dubinett S, Roth MD. Respiratory and immunologic consequences of marijuana smoking. J Clin Pharmacol. 2002;42(11 Suppl):71S-81S. doi: https://doi.org/10.1002/j.1552-4604.2002.tb06006.x

4. Tashkin DP, Shapiro BJ, Frank IM. Acute effects of smoked marijuana and oral delta9-tetrahydrocannabinol on specific airway conductance in asthmatic subjects. Am Rev Respir Dis. 1974;109(4):420-428.

5. Tashkin DP. Airway effects of marijuana, cocaine, and other inhaled illicit agents. Curr Opin Pulm Med. 2001;7(2):43-61. doi: https://doi.org/10.1097/00063198-200103000-00001

6. Aldington S, Williams M, Nowitz M, et al. Effects of cannabis on pulmonary structure, function and symptoms. Thorax. 2007;62(12):1058-1063.

doi: https://doi.org/10.1136/thx.2006.077081

7. Tashkin DP, Coulson AH, Clark VA, et al. Respiratory symptoms and lung function in habitual heavy smokers of marijuana alone, smokers of marijuana and tobacco, smokers of tobacco alone, and nonsmokers. Am Rev Respir Dis. 1987;135(1):209216.

8. Sherrill DL, Krzyzanowski M, Bloom JW, Lebowitz MD. Respiratory effects of non-tobacco cigarettes: A longitudinal study in general population. Int J Epidemiol. 1991;20(1):132-137. doi: https://doi.org/10.1093/ije/20.1.132

9. Taylor DR, Poulton R, Moffitt TE, Ramankutty P, Sears MR. The respiratory effects of cannabis dependence in young adults. Addiction. 2000;95(11):1669-1677.

doi: https://doi.org/10.1046/j.1360-0443.2000.951116697.x

10. Pletcher MJ, Vittinghoff E, Kalhan R, et al. Association between marijuana exposure and pulmonary function over 20 years. JAMA. 2012;307(2):173-181.

doi: https://doi.org/10.1001/jama.2011.1961

11. Kempker JA, Honig EG, Martin GS. The effects of marijuana exposure on expiratory airflow. A study of adults who participated in the U.S. National Health and Nutrition Examination Study. Ann Am Thorac Soc. 2015;12(2):135-141. doi: https://doi.org/10.1513/AnnalsATS.201407-333OC
12. Tan WC, Lo C, Jong A, et al. Marijuana and chronic obstructive lung disease: A population-based study. Can Med Assoc J. 2009; 180(8):814-820.

doi: https://doi.org/10.1503/cmaj.081040

13. Aldington $S$, Shirtcliffe $P$, Nowitz $M$, et al. Incidental findings from lung CT scans: implications for research. J Med Imaging Radiat Oncol. 2011;55(1):20-25.

doi: https://doi.org/10.1111/j.1754-9485.2010.02224.x

14. Couper D, LaVange LM, Han M, et al. Design of the Subpopulations and Intermediate Outcomes in COPD Study (SPIROMICS). Thorax. 2014;69(5):491-494. doi: https://doi.org/10.1136/thoraxjnl-2013-203897

15. Fabbri LM, Hurd SS, GOLD Scientific Committee. Global strategy for the diagnosis, management and prevention of COPD: 2003 update. Eur Respir J. 2003;22(1):1-2. doi: https://doi.org/10.1183/09031936.03.00063703

16. Wan ES, Castaldi PJ, Cho MH, et al. Epidemiology, genetics, and subtyping of preserved ratio impaired spirometry (PRISm) in COPDGene. Respir Res. 2014;15(1):89.

doi: https://doi.org/10.1186/s12931-014-0089-y

17. Sieren JP, Newell JD, Barr RG, et al. SPIROMICS protocol for multicenter quantitative computed tomography to phenotype the lungs. Am J Respir Crit Care Med. 2016;194(7):794-806. doi: https://doi.org/10.1164/rcem.201506-1208PP

18. Hasin DS, Saha TD, Kerridge BT, et al. Prevalence of marijuana use disorders in the United States between 2001-2002 and 20122013. JAMA Psychiatry. 2015;72(12):1235.

doi: https://doi.org/10.1001/jamapsychiatry.2015.1858

19. Arria AM, Caldeira KM, Bugbee BA, Vincent KB, O’Grady KE. Marijuana use trajectories during college predict health outcomes nine years post-matriculation. Drug Alcohol Depend. 2016;159:158-165.

doi: https://doi.org/10.1016/j.drugalcdep.2015.12.009

20. Tetrault JM, Crothers K, Moore BA, Mehra R, Concato J, Fiellin DA. Effects of marijuana smoking on pulmonary function and respiratory complications: a systematic review. Arch Intern Med. 2007; 167(3):221-228.

doi: https://doi.org/10.1001/archinte.167.3.221

21. Moore BA, Augustson EM, Moser RP, Budney AJ. Respiratory effects of marijuana and tobacco use in a U.S. sample. $J$ Gen Intern Med. 2005;20(1):33-37.

doi: https://doi.org/10.1111/j.1525-1497.2004.40081.x

22. Hancox RJ, Poulton R, Ely M, et al. Effects of cannabis on lung function: a population-based cohort study. Eur Respir J. 2010;35(1):42-47.

doi: https://doi.org/10.1183/09031936.00065009

23. Tashkin DP. Effects of marijuana smoking on the lung. Ann Am Thorac Soc. 2013;10(3):239-247.

doi: https://doi.org/10.1513/AnnalsATS.201212-127FR 
24. Fiorelli A, Accardo M, Vicidomini G, Messina G, Laperuta P, Santini M. Does cannabis smoking predispose to lung bulla formation? Asian Cardiovasc Thorac Ann. 2014;22(1):65-71. doi: https://doi.org/10.1177/0218492313478954

25. Thompson CS, White RJ. Lung bullae and marijuana. Thorax. 2002;57(6):563.

doi: https://doi.org/10.1136/thorax.57.6.563

26. Moore BA, Augustson EM, Moser RP, Budney AJ. Respiratory effects of marijuana and tobacco use in a U.S. sample. $J$ Gen Intern Med. 2005;20(1):33-37.

doi: https://doi.org/10.1111/j.1525-1497.2004.40081.x

27. Pletcher MJ, Vittinghoff E, Kalhan R, et al. Association between marijuana exposure and pulmonary function over 20 Years. JAMA. 2012;307(2):173.

doi: https://doi.org/10.1001/jama.2011.1961 